\title{
Safety and effectiveness of ceftaroline fosamil in children: a systematic review and meta-analysis
}

\author{
M. Teresa Rosanova, M.D. ${ }^{a}$, Norma Sberna, Pharmacist ${ }^{b}$ and Roberto Lede, M.D. ${ }^{c}$
}

\begin{abstract}
Introduction. Antibiotic resistance is an increasingly growing health problem worldwide, so it is imperative to look for new, more effective antibiotics. Ceftaroline has a broad spectrum of activity against clinically relevant Grampositive strains, including methicillin-resistant Staphylococcus aureus and resistant Streptococcus pneumoniae strains, as well as Gram-negative pathogens implicated in skin and soft tissue infections or community-acquired pneumonia; it is therefore a potential therapeutic option. We conducted a systematic review to assess whether ceftaroline was safer and more effective than comparators.
\end{abstract}

Material and methods. A comprehensive bibliographic search was done to identify experimental clinical trials that compared the safety and effectiveness of ceftaroline to a comparator in the pediatric population. The rate of therapeutic failure was used to determine the effectiveness, while the presence of any adverse event was considered for safety.

Results. Three studies were identified: two in community-acquired pneumonia and one in skin and soft tissue infections. No study showed a difference in the risk for therapeutic failure, relative risk (RR): $0.97(0.54-1.73)$, or safety criterion, RR: 0.79 (0.51-1.23).

Conclusions. The available evidence suggests that ceftaroline may be a valid therapeutic option for the management of skin and soft tissue infections or community-acquired pneumonia in pediatric patients. No studies with a highquality of evidence were observed in other types of infections or in patients admitted to the critical care unit.

Key words: ceftaroline, systematic review, effectiveness, safety.

http:/ / dx.doi.org/10.5546/aap.2019.eng.e205

To cite: Rosanova MT, Sberna N, Lede R. Safety and effectiveness of ceftaroline fosamil in children: a systematic review and meta-analysis. Arch Argent Pediatr 2019;117(3):e205-e210.
E-mail address:

M. Teresa Rosanova, M.D.: margris2@yahoo.com.ar

Funding:

None.

Conflict of interest:

None.

Received: 8-6-2018

Accepted: 12-10-2018

\section{INTRODUCTION}

The rise in antibiotic resistance poses an increasingly growing health problem worldwide. Methicillinresistant Staphylococcus aureus (MRSA) has become a common cause of complicated skin infections and pneumonia, among others, and this calls for the need to find new, safe and effective therapies.

Vancomycin is still the first-line option for patients with invasive MRSA infections, but its kidney toxicity, its narrow spectrum, and its low tissue level would warrant the search for new therapy options..$^{1-5}$

In 2011, the Infectious Diseases Society of America recommended vancomycin in doses of $15 \mathrm{mg} / \mathrm{kg}$ every 6 hours for children with invasive MRSA infections in order to reach high trough levels. ${ }^{1}$ This would allow to establish a vancomycin area under the curve that, in adults, would better predict effectiveness; however, after these recommendations were implemented, several authors reported that, in pediatric patients, there was an association between higher vancomycin doses and kidney failure. $^{2,3}$

Ceftaroline fosamil is a cephalosporin that has generated much interest as a potential treatment option. As in the case of other cephalosporins, the antibiotic activity of ceftaroline results from binding to essential proteins, which inhibits bacterial cell wall synthesis. Ceftaroline has a broad spectrum of activity against clinically relevant Gram-positive strains, including MRSA and resistant Streptococcus pneumoniae strains, as well as Gram-negative pathogens implicated in skin and soft tissue infections (SSTIs) or communityacquired pneumonia (CAP). 
This antibiotic was approved by the United States Food and Drug Administration (FDA) for its use in adults and children (as of 2 months old) with SSTIs caused by Staphylococcus aureus strains susceptible and resistant to methicillin, Streptococcus pyogenes, Streptococcus agalactiae, Escherichia coli, Klebsiella pneumoniae and Klebsiella oxytoca. It has also been approved for CAP caused by Streptococcus pneumoniae, methicillinsusceptible Staphylococcus aureus, Escherichia coli, Haemophilus influenzae, Klebsiella pneumonia and Klebsiella oxytoca. ${ }^{4-8}$ In Argentina, it was approved by the National Drug, Food and Technology Administration of Argentina (Administración Nacional de Medicamentos, Alimentos y Tecnología Médica, ANMAT), although the authorized package insert indicates that it should not be used in children and adolescents because there are not sufficient data in these populations.

The international experience with ceftaroline in the pediatric population is scarce, which encouraged us to make a systematic review of the existing evidence on this topic. The main objective of this review was to assess whether ceftaroline was safe and effective in children, especially in the case of SSTIs and CAP.

\section{MATERIAL AND METHODS}

A comprehensive bibliographic search was done; it is detailed in Table 1. Basically, the search terms were ceftaroline and ceftaroline fosamil, and the following filters were applied: clinical trial, review, comparative study, systematic reviews, randomized controlled trial (RCT), controlled clinical trial, meta-analysis, and use in human studies. Articles published in English, Spanish or French up to December 2017 were reviewed. The articles' references were checked manually to identify additional relevant studies. We selected articles that corresponded to studies conducted in the pediatric population.
The incidence of therapeutic failure was selected as the effectiveness endpoint based on the concept that, for treatment indication, a physician's primary interest was knowing the risk for not achieving the therapeutic goal, either due to ineffectiveness or safety reasons. A lower therapeutic failure rate suggested a better therapy performance. Safety was assessed by calculating the number of patients with at least one adverse event. Results were analyzed on an intention-totreat basis.

Study selection: two reviewers (MTR and NS) independently extracted data and performed a qualitative assessment of studies. In case of disagreement, a third reviewer (RL) analyzed data and coordinated scientific discussion until reaching consensus.

A study was included if: (1) it was a RCT, regardless of blinding, and (2) it compared safety and effectiveness of ceftaroline to other antibiotics in children. The methodological quality of studies was assessed using the Jadad scale; ${ }^{9}$ those that scored $\geq 2$ were considered for assessment.

Data analysis and statistical methods: the individual and common relative risk (RR) of each study, and the corresponding $95 \%$ confidence interval (CI) for the risk for therapeutic failure and the presence of adverse events, were estimated using the fixed-effect method (Mantel-Haenszel) or the random-effect model (DerSimonianLaird), based on the heterogeneity analysis. Estimations were done using the meta-analysis software proposed by the Critical Appraisal Skills Programme (CASPE).${ }^{10}$ The heterogeneity bias was estimated using Higgins' $I 2$ estimator. ${ }^{11}$ The publication bias was estimated using Egger's test. The null hypothesis was rejected if $p<0.05$. This report complies with the suggestions of the Preferred Reporting Items for Systematic Reviews and Meta-Analyses (PRISMA) statement. ${ }^{12}$

TABLE 1. Bibliographic search

\begin{tabular}{lccc}
\hline Database & Access platform & Date accessed & No. of studies \\
\hline Medline & Elsevier & $12 / 4 / 2017$ & 49 \\
Embase & Elsevier & $12 / 4 / 2017$ & 68 \\
CINAHL & EbscoHOST & $12 / 4 / 2017$ & 48 \\
Cochrane & Wiley Online Library & $12 / 4 / 2017$ & 59 \\
SCI-EXPANDED & WOS & $12 / 4 / 2017$ & 499 \\
Scopus & Elsevier & $12 / 4 / 2017$ & 918 \\
Total & & & 1641 \\
Duplicates & & & 620 \\
Total without duplicates & & & 1021 \\
\hline
\end{tabular}




\section{RESULTS}

\section{Included studies and main characteristics}

A total of 1021 potentially relevant abstracts were identified with the bibliographic search. Based on the review by title and abstract, 30 RCTs were selected.

Finally, three studies ${ }^{6-8}$ were selected for analysis and inclusion in this systematic review

FIGURE 1. Article search, assessment, and inclusion flow chart

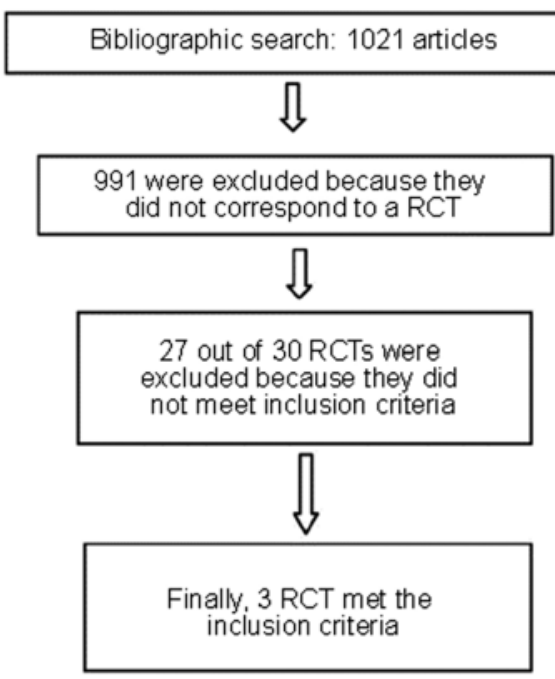

RCT: randomized controlled trial.
(Figure 1) because they met the above-mentioned eligibility criteria, with a total of 359 individuals. In two studies, ${ }^{7,8}$ patients had CAP (n: 181), whereas in the remaining study, six patients had SSTIs (n: 159).

Table 2 shows a summary of the main characteristics of included studies; Table 3 describes the risks for therapeutic failure for ceftaroline and the comparators (vancomycin ${ }^{6,7}$ and ceftriaxone $)^{8}$ in the main studies and the RR common obtained using the fixed-effect method, because there is no evidence of heterogeneity $(I 2=0)$. Figure 2 describes data as cumulative results, showing that there is no difference in the incidence of therapeutic failure between ceftaroline and comparators using either estimation method (random and fixed effects).

Table 4 describes the risk for adverse events. For this endpoint, the dataset is clearly heterogeneous $(I 2=56 \%)$. It may be because one of the studies (Blumer) ${ }^{7}$ reported a remarkable incidence of adverse events $(80 \%)$ in the comparator group versus only $40 \%$ in the ceftaroline group. Such phenomenon may probably be related to the scarce number of study subjects (n: 10) in the comparator group. Therefore, the safety meta-analysis is unreliable, and the RR common estimation may be avoided; however, if estimated, the valued obtained using the random-effect method should be considered,

TABLE 2. Characteristics of randomized controlled trials included in the study

\begin{tabular}{|c|c|c|c|c|}
\hline Author & Type of study & Characteristics of study & Endpoint & Jadad scale \\
\hline $\begin{array}{l}\text { Korczowski B et al. } \\
\text { Pediatr Infect Dis J. } \\
\text { 2016;35:e239-e247. }\end{array}$ & $\begin{array}{c}\text { Multicenter, } \\
\text { randomized, } \\
\text { observer-blinded, } \\
\text { active-controlled study. }\end{array}$ & $\begin{array}{c}\text { Patients with complicated SSTIs. } \\
\text { Age: } 2 \text { months old - } 17 \text { years old. } \\
\text { 2:1 randomization } \\
\text { to receive intravenous } \\
\text { ceftaroline fosamil (n: } 107 \text { patients) } \\
\text { or vancomycin or cefazoline } \\
\text { plus aztreonam (n: } 52) .\end{array}$ & $\begin{array}{c}\text { Clinical and } \\
\text { microbiological cure. - } \\
\text { Adverse events. }\end{array}$ & 2 \\
\hline $\begin{array}{l}\text { Blumer et al. } \\
\text { Pediatr Infec Dis J. } \\
\text { 2016;35:760. }\end{array}$ & $\begin{array}{l}\text { Multicenter, } \\
\text { randomized, } \\
\text { observer-blinded, } \\
\text { active-controlled study. }\end{array}$ & $\begin{array}{l}\text { Patients with community-acquired } \\
\text { pneumonia. } \\
\text { Age: } 2 \text { months old - } 17 \text { years old. } \\
\text { 3:1 randomization } \\
\text { ceftaroline fosamil (n: } 30) \\
\text { or ceftriaxone plus vancomycin (n: } 10) \text {. } \\
\text { Stratified by age range. }\end{array}$ & $\begin{array}{l}\text { Safety and } \\
\text { effectiveness. }\end{array}$ & 3 \\
\hline $\begin{array}{l}\text { Cannavino et al. } \\
\text { Pediatr Infect Dis J. } \\
\text { 2016;35:752-9. }\end{array}$ & $\begin{array}{l}\text { Multicenter, } \\
\text { randomized, } \\
\text { controlled study. } \\
\text { cefta }\end{array}$ & $\begin{array}{l}\text { Patients with community-acquired } \\
\text { pneumonia. } \\
\text { Age: } 2 \text { months old - } 17 \text { years old. } \\
\text { 3:1 randomization to receive } \\
\text { aroline fosamil (n: } 121) \text { or ceftriaxone (n: } \\
\text { Stratified by age range. }\end{array}$ & $\begin{array}{l}\text { Clinical and } \\
\text { microbiological course - } \\
\text { Adverse events. } \\
\text { 39). }\end{array}$ & 2 \\
\hline
\end{tabular}

SSTI: skin and soft tissue infections. 
as described in Table 4. The most commonly reported adverse events for ceftaroline included skin rash, fever, and gastrointestinal symptoms.

In the three included studies, the rate of seroconversion with the Coombs direct test was higher in the ceftaroline group than in the control groups; however, no case of hemolytic anemia was reported.

No publication bias was detected, either in the effectiveness analysis ( $p$ : 0.64) (see Figure 3 ) or in the safety analysis ( $p: 0.29$ ).

\section{DISCUSSION}

This systematic review was developed to assess the risk for therapeutic failure and the safety of ceftaroline in children versus available comparators.

The meta-analysis results showed that the risk for therapeutic failure and the incidence of adverse events were similar between ceftaroline and the comparator, which is consistent with the adequate therapeutic profile of cephalosporins. ${ }^{13}$

In relation to the individual analysis of the risk for therapeutic failure with ceftaroline in MRSA infections, only the study by Korczowski ${ }^{6}$ evidenced a better response with ceftaroline $(89 \%)$ versus the comparator $(57 \%)$ in SSTIs. Regarding the other two studies in $\mathrm{CAP}^{7,8}$ for the study by Cannavino, ${ }^{8}$ one of the exclusion criteria was MRSA isolation, because ceftriaxone was used for comparison and did not provide enough coverage against this pathogen; in the study by

TABLE 3. Risk for therapeutic failure

\begin{tabular}{lccc}
\hline Study & Ceftaroline & Comparator & Relative risk (95 \% CI) \\
\hline Korczowski et al., 2016 & $16 / 107$ & $8 / 52$ & $0.97(0.44-2.12)$ \\
n: 159 & $(14.9 \%)$ & $(15.4 \%)$ & $0.77(0.18-3.33)$ \\
Blumer et al., 2016 & $5 / 29$ & $2 / 9$ & \\
n: 38 & $(17.2 \%)$ & $(22.2 \%)$ & $1.09(0.38-3.14)$ \\
Cannavino et al., 2016 & $13 / 107$ & $4 / 36$ & \\
n: 143 & $(12.1 \%)$ & $(11.1 \%)$ & \\
RR & & & \\
Fixed-effect method & & $0.97(0.54-1.73)$ & \\
\hline
\end{tabular}

Heterogeneity test. Q: 0.13; p: 0.93; I2: $0 \%$.

$\mathrm{CI}$ : confidence interval; RR: relative risk.

FIGURE 2. Forest plot of the risk for therapeutic failure. Cumulative meta-analysis

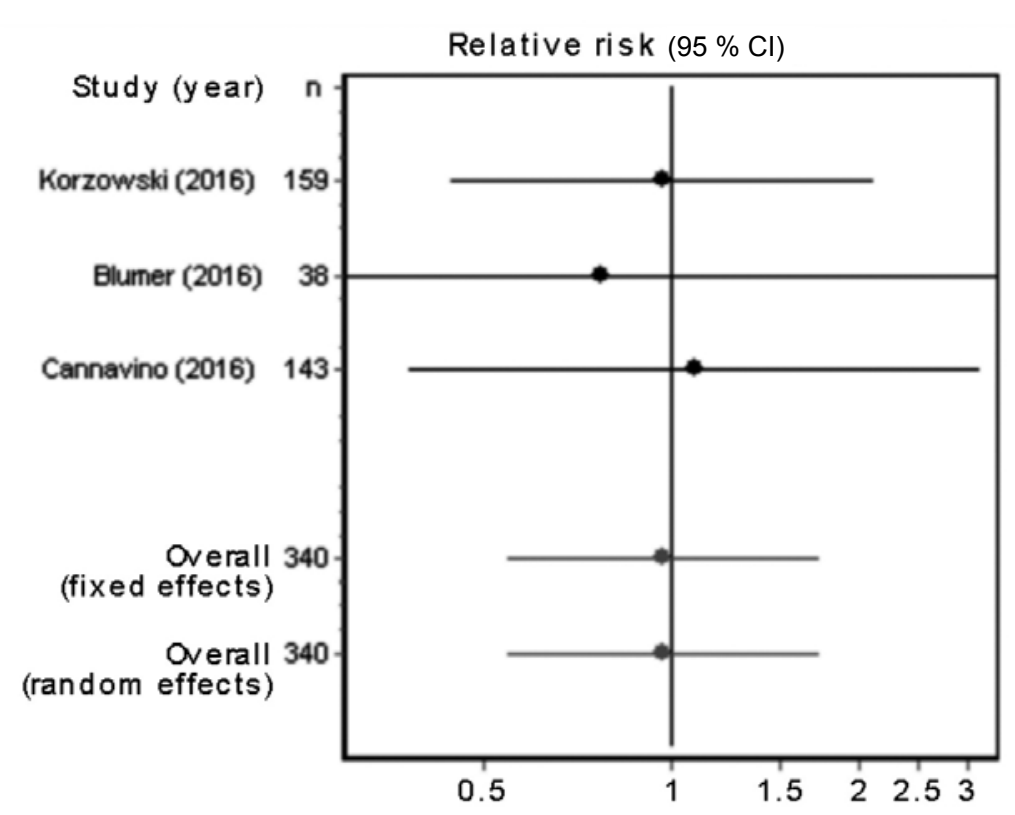

CI: confidence interval. 
Blumer, ${ }^{7}$ the incidence of MRSA isolation was very low, so it was not possible to make valid conclusions about this aspect. In addition, in this study, ceftaroline doses were higher than those approved by the FDA. However, the incidence of adverse events was lower in this group. The small sample size of this study precluded us from making a reliable interpretation of results.

In CAP, ceftriaxone is the only cephalosporin that has demonstrated to be superior to penicillin in S. pneumoniae, including penicillin-resistant strains. ${ }^{14}$

In the case of complicated pneumonia and patients admitted to the intensive care unit, empiric antibiotic therapy should be broadened to cover other pathogens, such as MRSA; ${ }^{1}$ in the case of vancomycin-refractory or -intolerant patients, ceftaroline may be considered a therapeutic option in spite of the small available evidence.

In other infections, such as endocarditis, osteoarticular infections, sepsis, central nervous system infections, and bacteremia, only case series were found that showed adequate results with ceftaroline fosamil; however, these conclusions corresponded to studies whose designs had a lower internal validity and were not included in this study analysis. ${ }^{15-18}$

At present, the FDA has approved ceftaroline for CAP and SSTIs that require hospitalization in children older than 2 months.

TABLE 4. Safety (patients with at least one adverse event)

\begin{tabular}{lccc}
\hline Study & Ceftaroline & Comparator & RR (95\% CI) \\
\hline Korczowski et al., 2016 & $23 / 106$ & $12 / 53$ & $0.96(0.52-1.77)$ \\
n: 159 & $(21.7 \%)$ & $(22.6 \%)$ & $0.50(0.29-0.86)$ \\
Blumer et al., 2016 & $12 / 30$ & $8 / 10$ & \\
n: 40 & $(40 \%)$ & $(80 \%)$ & $0.98(0.67-1.46)$ \\
Cannavino et al., 2016 & $55 / 121$ & $18 / 39$ & $(46.1 \%)$
\end{tabular}

$\mathrm{RR}_{\text {common }}$

Random-effect method

$0.79(0.51-1.23)$

Heterogeneity test. Q: 4.59; p: 0.10; I2: $56 \%$ (0-88).

$\mathrm{RR}$ : relative risk; $\mathrm{CI}$ : confidence interval.

FIGURE 3. Funnel plot (Egger's chart) for the publication bias for therapeutic failure criterion

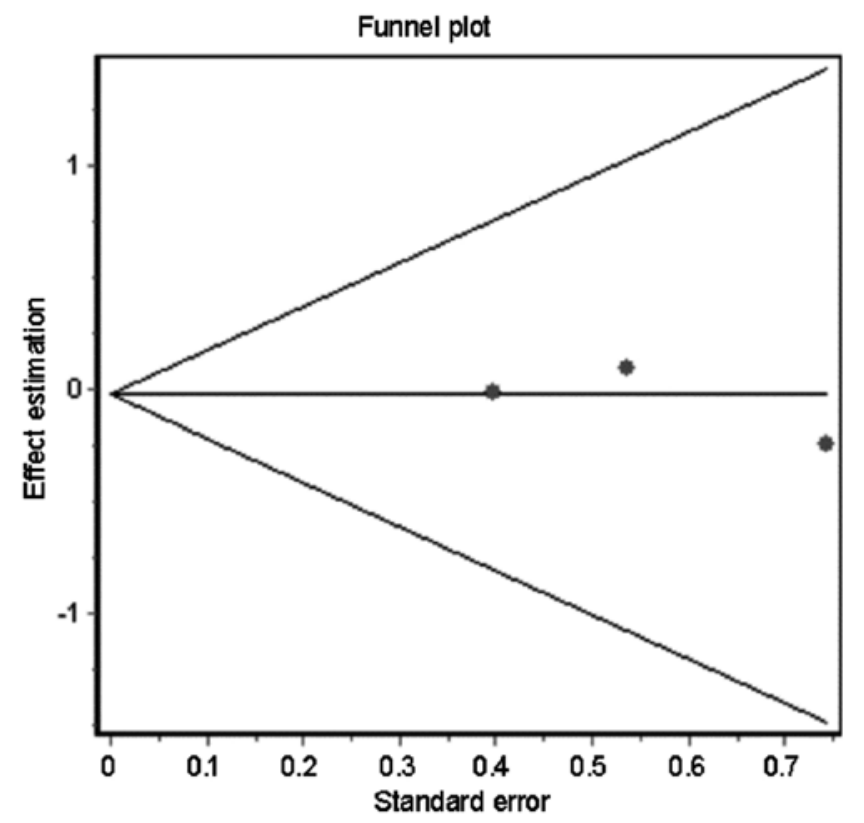


One of the limitations of this study was that included RCTs were only done in patients with CAP or SSTIs and who were not admitted to the intensive care unit and had few MRSA microbiological isolations, thus restricting the extent of conclusions.

The low statistical power of the few adequate studies for inclusion was also a limitation. Based on the evidence described here, and considering the pharmacokinetic advantages offered by ceftaroline treatment, further strict clinical studies should be carried out to obtain definite information about the safety and effectiveness of ceftaroline in CAP and SSTIs and in other invasive MRSA infections.

\section{CONCLUSIONS}

The synthesis of the published experimental evidence demonstrates that ceftaroline mono therapy was not different from its comparators in terms of safety or effectiveness, so it should be considered for study as an additional antibiotic therapy for the management of pediatric patients with CAP or SSTIs who are intolerant or refractory to conventional treatments.

New experimental, controlled studies are required to assess the role of treatment, also in patients admitted to the intensive care unit and with MRSA isolation, as well as in other infections.

\section{REFERENCES}

1. Liu C, Bayer A, Cosgrove, S, Daum R, et al. Clinical Practice Guidelines by the Infectious Diseases Society of America for the Treatment of Methicillin-Resistant Staphylococcus aureus Infections in Adults and Children. Clin Infect Dis. 2011; 52(3):e18-55.

2. Knoderer CA, Nichols KR, Lyon KC, Veverka MM, et al. Are elevated vancomycin serum trough concentrations achieved within the first 7 days of therapy associated with acute kidney injury in children? J Pediatric Infect Dis Soc. 2014; 3(2):127-31.

3. McKamy S, Hernandez E, Jahng M, Moriwaki T, et al. Incidence and risk factors influencing the development of vancomycin nephrotoxicity in children. J Pediatr. 2011; 158(3):422-6.
4. Yim J, Molloy LJ, Newland G. Use of Ceftaroline Fosamil in Children: Review of Current Knowledge and its Application. Infect Dis Ther. 2017; 6(1):57-67.

5. Kiang TK, Wilby KJ, Ensom MH. A critical review on the clinical pharmacokinetics, pharmacodynamics, and clinical trials of ceftaroline. Clin Pharmacokinet. 2015; 54(9):915-31.

6. Korczowski B, Antadze T, Giorgobiani M, Stryjewski ME, et al. A Multicenter, Randomized, Observer-blinded, Activecontrolled Study to Evaluate the Safety and Efficacy of Ceftaroline Versus Comparator in Pediatric Patients with Acute Bacterial Skin and Skin Structure Infection. Pediatr Infect Dis J. 2016; 35(8):e239-47.

7. Blumer JL, Ghonghadze T, Cannavino C, $\mathrm{O}^{\prime} \mathrm{Neal} \mathrm{T}$, et al. A Multicenter, Randomized, Observer-blinded, Activecontrolled Study Evaluating the Safety and Effectiveness of Ceftaroline Compared with Ceftriaxone plus Vancomycin in Pediatric Patients with Complicated Community-acquired Bacterial Pneumonia. Pediatr Infect Dis J. 2016; 35(7):760-6.

8. Cannavino CR, Nemeth A, Korczowski B, Bradley JS, et al. A Randomized, ProspectiveStudy of Pediatric Patients with Community-acquired Pneumonia Treated with Ceftaroline versus Ceftriaxone. Pediatr Infect Dis J. 2016; 35(7):752-9.

9. Jadad AR, Moore RA, CarrolD, Jenkinson C, et al. Assessing the quality of reports of randomized clinical trials: is blinding necessary? Control Clin Trials. 1996; 17(1):1-12. 10.

10. Critical Appraisal Skills Programme Español (CASPe). Calculadoras. [Accessed on: December 12 $\left.{ }^{\text {th }}, 2018\right]$. Available at:http: / / www.redcaspe.org/herramientas/calculadoras.

11. Higgins JP, Thompson SG. Quantifying heterogeneity in a meta-analysis. Stat Med. 2002; 21(11):1539-58.

12. MoherD, Liberati A, TetzlaffJ, AltmanDG;PRISMA Group. Preferred reporting items for systematic reviews and metaanalyses: the PRISMA statement. BMJ. 2009; 339:b2535.

13. El Hajj M, Turgeon R, Wilby K. Ceftarolinefosamil for community-acquired pneumonia and skin and skin structure infections: a systematic review. Int J Clin Pharm. 2017; 39(1):26-32.

14. Lopardo HA, Fossati S. Viviendo treinta años con el enemigo: neumococos resistentes a los antibióticos en la Argentina. Acta Bioquím Clín Latinoam. 2016; 50(4):693-712.

15. Cosimi R, BeikN,KubiakD, Johnson J. Ceftaroline for Severe Methicillin-Resistant Staphylococcus aureus Infections: A Systematic Review. Open Forum Infect Dis. 2017;4(2):ofx084.

16. HorcajadaJ, CantónR. Ceftarolina, unnuevoantimicrobiano de amplioespectro en la era de las multirresistencias. Enferm Infecc Microbiol Clin. 2014; 32(Supl 2):1-7.

17. Pasquale TR, Tan MJ, Trienski TL, File TM Jr. Methicillinresistant Staphylococcus aureus nosocomial pneumonia patients treated with ceftaroline: retrospective case series of 10 patients. J Chemother. 2015; 27(1):29-34.

18. Casapao AM, Davis SL, Barr VO, Klinker KP, et al. Large retrospective evaluation of the effectiveness and safety of ceftarolinefosamil therapy. Antimicrob Agents Chemother. 2014; 58(5):2541-6. 